\title{
PENINGKATAN KETERAMPILAN MENYUSUN RPP MELALUI METODE BIMBINGAN KELOMPOK GURU SDN GEDANGAN 3 TAHUN 2018/2019
}

\author{
Muhammad Ali Murtadlo \\ SDN Gedangan 3 Kabupaten Jombang \\ Email:m_ali_murtadlo@yahoo.com
}

\begin{abstract}
The real condition shows that all teachers of SDN Gedangan 3 (8 people) have RPP result dowload from internet without revision. This RPP is not fully structured and systematic, not used, only complements administrative obligations. The solution resolves through the School Action Research with the title "Improving Skills of Preparing RPP through Teacher Group Guidance Methods SDN Gedangan 3 Year 2018/2019". The study was conducted in two cycles. Instrument data collection using writing test preparation RPP, observation sheet, and interview guidelines. The result is: 1) The RPP value compiled by the teacher has increased; 2) After following group guidance, all teachers have high skill in preparing RPP. This proves that the guidance of the group can improve the skills of teachers SDN Gedangan 3 in the preparation of RPP.
\end{abstract}

Keywords: skill of preparing RPP, group guidance method, improvement

Abstrak: Kondisi riil menunjukkan semua guru SDN Gedangan 3 memiliki RPP hasil download dari internet tanpa revisi. RPP ini tidak tersusun secara lengkap dan sistematis, tidak digunakan, hanya melengkapi kewajiban administrasi. Solusi mengatasinya melalui Penelitian Tindakan Sekolah dengan judul "Peningkatan Keterampilan Menyusun RPP melalui Metode Bimbingan Kelompok Guru SDN Gedangan 3 Tahun 2018/2019". Penelitian ini diadakan dalam dua siklus. Instrument pengumpulan data menggunakan tes tulis, lembar observasi, dan pedoman wawancara. Hasilnya adalah: 1) Nilai RPP yang disusun oleh guru mengalami peningkatan; 2) Setelah mengikuti bimbingan kelompok, seluruh guru telah memiliki keterampilan yang tinggi dalam penyusunan RPP. Hal ini membuktikan bahwa bimbingan kelompok yang dilakukan dapat meningkatkan keterampilan guru SDN Gedangan 3 dalam penyusunan RPP.

Kata Kunci: keterampilan menyusun RPP, metode bimbingan kelompok, peningkatan

Seorang guru profesional harus dapat mempertanggungjawabkan pembelajaran yang dikelolanya (Tim FKIP, 2007:12). Agar dapat mengelola pembelajaran dengan baik maka guru harus merencanakan setiap tahapan pengelolaan pembelajaran yang akan dilakukan. Sebagaimana yang diungkapkan oleh Young bahwa Instructional planning is one of the most important professional activities teachers engage in" (Young, Reiser, \& Walter, 1998). Stark juga mengungkapkan "Course planning is an important faculty role requiring expertise and effective decision making" (Stark, 2000). Perencanaan pembelajaran dilakukan sebelum proses pembelajaran dimulai, sebagaimana pernyataan berikut ini "Planning is one of the professional tasks teachers have to carry out before their direct action in the classrooms" (Ramı, 2017). Hal ini dimaksudkan agar pembelajaran berlangsung secara interaktif, inspiratif, menyenangkan, menantang, memotivasi peserta didik untuk berpartisipasi aktif, serta memberikan ruang yang cukup bagi prakarsa, kreativitas, kemandirian sesuai dengan bakat, minat, dan perkembangan fisik serta psikologis peserta didik (Permendikbuad No. 22 tahun 2016: 8). Berdasarkan fenomena yang terjadi, perlu dicari solusi yang tepat agar guru SDN Gedangan 3 dapat menyusun RPP yang baik dan benar sesuai dengan standar 
proses. Selain itu pembelajaran yang baik juga mengaitkan struktur dan proses keilmuan dengan isu terkini sebagaimana pernyataan berikut ini "it's important to develop discipline specific curriculum, and also describes the structures and processes to be used to build connections between those disciplines and to ensure that current issues are addressed" (Sullivan, Clarke, Clarke, Farrell, \& Gerrard, 2013). Selanjutnya RPP yang disusun digunakan untuk kepentingan pembelajaran sehingga dapat mengembangkan kompetensi peserta didik secara optimal. Karena seringkali apa yang diinginkan oleh guru tidak terlaksana dengan baik "there were fundamental $d \sim$ :erences between the teacher's thinking and teaching processes" (Moatlem, 1998). Kegiatan yang dimaksud ini dapat ditempuh melalui Penelitian Tindakan Sekolah (PTS) dengan judul "Peningkatan Keterampilan Menyusun RPP melalui Metode Bimbingan Kelompok Guru Kelas SDN Gedangan 3 Kecamatan Sumobito Tahun 2018/2019". Bimbingan kelompok dianggap efektif karena anggota kelompok setelah mendapatkan bimbingan dapat mengimbaskan kepada guru lainnya agar mendapat pemahaman yang benar. Hal tersebut karena "In classroom practice subject matter knowledge is part of a professional practice, developing on the basis of discipline knowledge, a value and goal system, an action repertoire and occupational knowledge in teaching practice and interaction with students, colleagues, teacher educators, researchers or parents." (Lang \& Olson, 2000). Pelaksanaan bimbingan kelompok dapat diadakan secara berkala dan dipilih waktu yang tidak menganggu jam efektif mengajar. "A key to improving these efforts is to understand local practice and use these insights to design more locally attuned interventions" (Hora \& Holden, 2013). Melalui bimbingan kelompok diharapkan mampu mengakomodasi seluruh guru SDN Gedangan 3 dalam rangka penyusunan RPP yang baik dan benar dengan berpedoman pada standar proses. Hal tersebut sesuai dengan pernyataan bahwa "Improving teachers' quality can be strengthening learning process" (Muganyizi et al., 2014).
Dipilihnya bimbingan kelompok untuk meningkatkan keterampilan guru SDN Gedangan 3 dalam menyusun RPP, selain memiliki kelebihan sebagaimana yang diuraikan sebelumnya, juga dengan beberapa pertimbangan, antara lain: 1) SDN Gedangan 3 memiliki sarana yang terbatas; 2) terdapat perbedaan kemampuan individual para guru dalam belajar, 3) terdapat perbedaan kemampuan individual para guru dalam minat belajar, dan 4) beberapa unit pekerjaan yang dibimbingkan ini perlu diselesaikan dalam waktu yang bersamaan. Sebagaimana yang diungkapkan Eley "Teachers' conceptions of teaching, and broad approaches to teaching reported by teachers are both commonly found to range from teaching as information transmission, through to teaching as supporting students' own knowledge constructions" (Eley, 2006).

\section{METODE PENELITIAN}

Penelitian ini diadakan di SDN Gedangan 3 bagi seluruh guru dengan menggunakan jenis penelitian tindakan sekolah selama dua siklus. Setiap siklus meliputi planning (rencana), action (tindakan), observation (pengamatan), dan reflection (refleksi). Siklus I tanggal 14 dan 15 November 2018, materi dititikberatkan pada pengembangan RPP sesuai Permendikbuad Nomor 22 tahun 2016 tentang Standar Proses. Siklus II tanggal 21 November 2018 materi revisi RPP. Instrument pengumpulan data menggunakan tes tulis penyusunan RPP, lembar observasi, dan pedoman wawancara. Data yang didapat diolah secara deskriptif kuantitatif dengan memanfaatkan statistika sederhana.

\section{HASIL DAN PEMBAHASAN Siklus I}

Tahap perencanaan tindakan siklus 1 yang dilakukan oleh kepala sekolah adalah 1). Menentukan subjek penelitian, yaitu seluruh guru SDN Gedangan 3 dengan tujuan untuk meningkatkan keterampilan dalam penyusunan RPP; 2) Menyusun materi bimbingan beserta alat yang diperlukan berupa pedoman penyusunan RPP; 3). Menentukan waktu pelaksanaan bimbingan; 4) Menyusun format penilaian RPP; dan 5) Menentukan kriteria 
keberhasilan tindakan sebesar $80 \%$. Siklus yang pertama terdiri dari dua pertemuan bimbingan yang dilakukan pada tanggal 14 dan 15 November 2018 pukul 12.00-14.00 Wib. Pembelajaran pertama, materi difokuskan pada kegiatan mencermati Permendikbuad Nomor 22 tahun 2016 tentang Standar Proses. Selanjutnya guru diberi kesempatan untuk berdiskusi dengan teman sejawatnya tentang materi yang dipelajari. Saat diskusi permasalahan pokok yang menjadi kendala adalah menentukan dan mengembangkan indikator pencapaian kompetensi. Mayoritas guru SDN Gedangan 3 masih belum memiliki keterampilan untuk mengembangkan KD menjadi beberapa indikator pencapaian kompetensi. Meskipun terdapat sebagian guru bisa menentukan indikator dari KD tetapi belum dapat menjelaskan dan membimbing teman lainnya. Melihat kondisi demikian, peneliti menjelaskan cara mengembangkan KD menjadi indikator pencapaian kompetensi. Sesudah seluruh guru bisa membuat dan mengembangkan KD menjadi beberapa indikator, pertemuan hari itu diakhiri. Untuk komponen RPP yang lain akan dibahas pada pertemuan ke dua.

Langkah yang ditempuh kepala sekolah pada tahap ini sesuai petunjuk yang disampaikan oleh Ainamulyana (2012) tentang beberapa hal yang dapat dilakukan dalam melaksanakan metode belajar kelompok. Bila ada persoalan yang tidak dapat dipecahkan atau tidak ada kesepakatan antar anggota, tangguhkan saja untuk dimintakan pendapatnya kepada pendidik. Lanjutkan saja kepada persoalan yang lain.

Pertemuan ke dua siklus I dilaksanakan hari Kamis tanggal 19 November 2018. Pertemuan ini melanjutkan materi yang sudah dibahas pada pertemuan sebelumnya. Membahas tentang tujuan pembelajaran sampai dengan sumber belajar. Pada tahap ini, guru mempelajari isi Permendikbuad 41, selanjtnya melakukan diskusi dengan teman sejawat seperti pertemuan pertama. Masalah yang ditemukan pada saat diskusi adalah cara menentukan tujuan pembelajaran. Hampir seluruh guru belum dapat menentukan tujuan pembelajaran secara tepat. Kebanyakan guru-guru menganggap bahwa indikator pencapaian kompetensi sama dengan rumusan tujuan pembelajaran. Letak perbedaan hanya pada penambahan kata "siswa" belaka. Untuk memfasilitasi hal ini, peneliti mengambil langkah sebagaimana pada pertemuan pertama. Peneliti menjelaskan cara membuat tujuan pembelajaran yang memuat karakteristik "ABCD". Sesudah seluruh guru bisa membuat tujuan pembelajaran, peneliti meminta seluruh guru untuk melakukan unjuk kerja dalam membuat RPP dalam satu kali pertemuan. Peneliti berpesan agar seluruh guru ketika membuat RPP berpedoman pada materi yang sudah dipejari. Seluruh guru membuat RPP dengan perasaan senang. Selesai pertemuan pada pukul $14.30 \mathrm{Wib}$, melebihi 30 menit dari jadwal yang ditentukan. Kegiatan ini dilakukan secara berkelompok, saling membantu antara anggota satu dengan yang lain.

Langkah yang ditempuh oleh kepala sekolah ini sesuai dengan jenis-jenis metode bimbingan kelompok yang disampaikan oleh Tohirin (2007: 290). Tohirin menyatakan bahwa metode bimbingan kelompok dapat dilakukan dengan cara diskusi kelompok dan kegiatan kelompok. Diskusi kelompok merupakan suatu cara di mana para pendidik yang merupakan anggota kelompok bimbingan memperoleh kesempatan untuk memecahkan masalah secara bersamasama. Setiap pendidik memperoleh kesempatan untuk mengemukakan pikirannya masing-masing dalam memecahkan suatu masalah. Dalam melakukan diskusi kepala sekolah bertindak sebagai pemimpin kegiatan kelompok tersebut. Tohirin menjelaskan pula, kegiatan kelompok dapat menjadi suatu teknik yang baik dalam bimbingan, karena kelompok dapat memberikan kesempatan pada individu untuk berpartisipasi secara baik. Melalui kegiatan kelompok dapat mengembangkan bakat dan menyalurkan dorongan-dorongan tertentu dan pendidik dapat menyumbangkan pemikirannya. Dengan demikian muncul tanggung jawab dan rasa percaya diri.

Semua data yang diungkapkan pada refleksi I ini sesuai dengan data pelaksanaan tindakan dan observasi siklus I. Hasilnya menunjukkan bahwa sebagian besar guru SDN Gedangan 3 masih belum 
memiliki keterampilan yang baik dalam menyusun RPP. Nilai rata-rata yang diperoleh guru SDN Gedangan 3 hanya $67,75 \%$ dengan kategori kurang baik. Kondisi demikian menunjukkan bahwa siklus II penelitain tindakan sekolah ini masih diperlukan. Harapan dilanjutkannya proses bimbingan pada siklus II adalah seluruh guru SDN Gedangan 3 memiliki keterampilan yang tinggi dalam menyusun RPP. Meskipun demikian, jika dibandingkan dengan kondisi sebelum siklus, akan tampak peningkatan yang cukup signifikan. Berikut tabel perbandingannya.

Berdasarkan hasil diskusi dengan teman sejawat pada proses kegiatan refleksi menunjukkan, beberapa kelemahan di atas ternyata disebabkan oleh beberapa hal antara lain: a) Kepala sekolah kurang memberikan bimbingan secara cukup dan merata kepada seluruh subyek penelitian sehingga keterampilan mereka dalam membuat RPP tidak merata; b) Kepala sekolah kurang intens dalam memberikan bimbingan agar guru-guru SDN Gedangan 3 melaksanakan penyusunan RPP sesuai dengan langkah-langkah yang disajikan sebagaimana isi Permendikbuad Nomor 22 tahun 2016; c) Guru yang memiliki kecepatan belajar di atas rata-rata tidak dimanfaatkan untuk menjadi tutor sebaya; d) Seluruh komponen RPP tidak dibahas secara detail satu demi satu sehingga RPP yang dihasilkan guru masih belum memperhatikan penyusunan RPP yang baik sesuai amanat Pertmendiknas Nomor 22 tahun 2016; dan e) Seluruh anggota kelompok tidak melaksanakan kegiatan sesuai dengan langkah-langkah yang ditetapkan dalam metode bimbingan

Hasil wawancara menunjukkan, guruguru memberikan tanggapan positif terhadap proses bimbingan yang diberikan. Mereka menyatakan mendapat pengalaman baru. Mereka juga mengungkapkan bahwa keengganan untuk bertanya disebabkan beberapa hal, di antaranya adalah: 1) mereka merasa sudah mampu karena sudah mengikuti beberapa pelatihan. Selesai penilaian RPP, baru sadar betul bahwa kemampuan mereka masih membutuhkan bimbingan untuk terus ditingkatkan; 2) malu bertanya karena khawatir ketidakbisaannya diketahui oleh teman lain; 3) informasi yang didapat selama ini tentang RPP beraneka ragam; dan 4) kebanyakan diklat-diklat yang diikuti tentang pengembangan RPP kurang mendapat bimbingan secara intens sehingga pemahaman terhadap RPP sesuai dengan persepsi mereka masing-masing.

\section{Siklus II}

Tindakan yang dilakukan oleh kepala sekolah pada tahap perencanaan siklus II sesuai dengan hasil rekomendasi siklus 1, untuk menyempurnakan tindakan bimbingan penyusunan RPP pada siklus II. Tindakan baru yang dilakukan kepala sekolah pada siklus II ini adalah menyiapkan contoh RPP sesuai amanat Permendikbuad Nomor 22 tahun 2016 tentang Standat Proses. RPP contoh ini kemudian digandakan untuk digunakan sebagai acuan oleh guru-guru dalam membuat RPP. Selain itu kepala sekolah juga melengkapi catatan perbaikan pada RPP guru yang sudah dibuat pada siklus I untuk diadakan revisi kembali sehingga menghasilkan RPP menjadi benar. Catatan ini ditulis melekat pada bagian yang dinyatakan kurang memenuhi kriteria sesuai kietentuan. Hal ini dapat membantu guru dalam proses perbaikan RPP. Tindakan lain yang disiapkan oleh kepala sekolah sama dengan persiapan pada siklus 1 dengan beberapa penyempurnaan. Tindakan yang dimaksud adalah menyiapkan Outline, menentukan waktu pelaksanaan bimbingan, menyiapkan format penilaian RPP, menentukan kriteria keberhasilan tindakan.

Pada saat masing-masing kelompok melaksanakan tugas revisi RPP, kepala sekolah memantau proses kerja guru satu per satu dan memberikan bimbingan sesuai yang dibutuhkan. Langkah ini pun sudah sesuai dengan hakikat bimbingan kelompok. Bimbingan kelompok merupakan suatu cara memberikan bantuan kepada individu melalui kegiatan kelompok. Bimbingan kelompok merupakan sarana untuk menunjang perkembangan optimal masingmasing peserta didik dan diharapkan dapat mengambil manfaat dari pengalaman pendidikan bagi dirinya sendiri (Winkel dan Hastuti, 2004: 565). Sementara itu, Sukardi (2008: 64) menyatakan hal yang sama mengenai bimbingan kelompok, yakni layanan bimbingan yang memungkinkan sejumlah peserta didik secara bersamasama memperoleh berbagai bahan dari 
narasumber tertentu (terutama dari pembimbing) yang berguna untuk menunjang kehidupannya sehari-hari baik individu maupun pelajar, anggota keluarga dan masyarakat serta untuk pertimbangan dalam pengambilan keputusan.

Hasil bimbingan kelompok dalam penyusunan RPP yang dicapai guru-guru SDN Gedangan 3, tampak seluruh guru SDN Gedangan 3 sudah memiliki keterampilan tinggi dalam penyusunan RPP. Seluruhnya memperoleh nilai RPP di atas 96\% dengan kategori Baik Sekali. Nilai RPP guru-guru SDN Gedangan 3 sesudah siklus II sudah sangat baik, seluruhnya memperoleh minimal 92\%, bahkan sebanyak 6 orang (75\%) mencapai nilai $100 \%$. Seluruhnya melampaui indikator keberhasilan sebesar $89 \%$ sehingga dinyatakan tuntas belajar. Adapun nilai ratarata keberhasilan mereka pada siklus II adalah $98 \%$.

Nilai RPP disusun oleh seluruh guru SDN Gedangan 3 mulai dari sebelum mengikuti bimbingan kelompok dalam penyusunan RPP sampai dengan berakhirnya siklus II, terus mengalami peningkatan. Nilai rata-rata RPP pra siklus hanya $60,37 \%$, meningakat secara berturutturut pada siklus I dan II yakni $68,87 \%$ dan $98,5 \%$. Hal ini membuktikan bahwa bimbingan kelompok yang dilakukan oleh kepala sekolah dapat meningkatkan keterampilan guru-guru SDN Gedangan 3 dalam penyusunan RPP.

Capaian ini menunjukkan bahwa guruguru SDN Gedangan 3 sudah memiliki keterampilan menyusun RPP secara lengkap dan sistematis sebagaimana amanat Permendikbuad Nomor 22 tahun 2016 tentang Standar Proses untuk Satuan Pendidikan Dasar dan Menengah yang menyatakan, setiap pendidik pada satuan pendidikan berkewajiban menyusun RPP secara lengkap dan sistematis agar pembelajaran berlangsung secara interaktif, inspiratif, menyenangkan, menantang, memotivasi peserta didik untuk berpartisipasi aktif, serta memberikan ruang yang cukup bagi prakarsa, kreativitas, dan kemandirian sesuai dengan bakat, minat, dan perkembangan fisik serta psikologis peserta didik.

Terampilnya guru-guru SDN Gedangan 3 dalam menyusun RPP secara baik dan benar diharapkan menjadikan pembelajaran di kelas yang menjadi tanggung jawabnya dapat berlangsung secara interaktif, inspiratif, menyenangkan, menantang, memotivasi peserta didik untuk berpartisipasi aktif, serta memberikan ruang yang cukup bagi prakarsa, kreativitas, kemandirian sesuai dengan bakat, minat, dan perkembangan fisik serta psikologis peserta didik. Jika kondisi demikian dapat diciptakan, efektifitas pembelajaran dapat dicapai sehingga kompetensi peserta didik akan terus meningkat secara signifikan menuju manusia Indonesia yang berkualitas.

\section{SIMPULAN DAN SARAN}

Simpulan penelitian ini disajikan untuk menjawab tujuan penelitian: 1) Keterampilan guru dalam menyusun RPP dapat ditingkatkan melalui aktifitas bimbingan kelompok. Seluruh guru dapat menghasilkan RPP revisi pada tingkat yang memuaskan karena melampaui target keberhasilan sebesar $80 \%$. 2) Pelaksanaan bimbingan kelompok terhadap guru SDN Gedangan 3 sesuai dengan harapan. Guru SDN Gedangan 3 memiliki keterampilan tinggi dalam penyusunan RPP sesudah mengikuti bimbingan kelompok yang dilakukan oleh kepala sekolah. Nilai RPP guru-guru SDN Gedangan 3 pada siklus II sudah sangat baik, seluruhnya memperoleh minimal $92 \%$, bahkan sebanyak 6 orang (75\%) mencapai nilai $100 \%$, melampaui indikator keberhasilan sebesar 89\% sehingga dinyatakan tuntas belajar. Adapun nilai rata-rata keberhasilan mereka pada siklus II adalah 98\%. Capain ini membuktikan bahwa metode bimbingan kelompok benar-benar dapat meningkatkan keterampilan guru-guru SDN Gedangan 3 dalam menyusun RPP sesuai dengn Standar Proses.

Saran bagi kepala sekolah selaku agar tetap memberikan bimbingan secara intensif dan dilakukan secara tuntas kepada guru, baik secara invidu maupun kelompok sehingga keterampilan mereka dalam penyusunan RPP terus meningkat. Bagi guru yang memiliki kecepatan belajar di atas rata-rata dapat dimanfaatkan untuk menjadi tutor sebaya. Hal ini mempercepat pencapaian tujuan bimbingan penyusunan RPP. Lebih penting, perlu ditelusuri 
efektifitas penggunaan bimbingan kelompok untuk meningkatkan keterampilanketerampilan guru lainnya sehingga terwujud guru profesional dan bermartabat yang dapat menghantarkan putera terbaik bangsa dalam mewujudkan cita-citanya.

\section{DAFTAR PUSTAKA}

Eley, M. G. (2006). Teachers ' conceptions of teaching, and the making of specific decisions in planning to teach. 191214. https://doi.org/10.1007/s10734004-6382-9

Hora, M. T., \& Holden, J. (2013). Exploring the role of instructional technology in course planning and classroom teaching : implications for pedagogical reform. 68-92.

https://doi.org/10.1007/s12528-0139068-4

Lang, M., \& Olson, J. (2000). Integrated Science Teaching as a Challenge for Teachers to Develop New Conceptual Structures. 30(2), 213-224.

Moatlem, M. (1998). An Expert Teacher's Thinking and Teaching and Instructional Design Models and Principles: An Ethnographic Study. 46(2), 37-64.

Muganyizi, P. S., Ishengoma, J., Kanama, J., Kikumbih, N., Mwanga, F., Killian, R., \& Mcginn, E. (2014). An analysis of pre-service family planning teaching in clinical and nursing education in Tanzania. 1-9.

Ramı, E. (2017). Planning and Doing in Professional Teaching Practice. A Study with Early Childhood Education Teachers Working with ICT. 713-725. https://doi.org/10.1007/s10643-0160806-x

Stark, J. S. (2000). Planning introductory college courses : Content, context and form. 413-438.

Sukardi. (2008). Metodologi Penelitian Pendidikan, Kompetensi dan Praktiknya. Jakarta : PT. Bumi Aksara.

Sullivan, P., Clarke, D. J., Clarke, D. M., Farrell, L., \& Gerrard, J. (2013). Processes and priorities in planning mathematics teaching. 457-480. https://doi.org/10.1007/s13394-0120066-z

Tohirin. (2007). Bimbingan dan Konseling di Sekolah dan Madrasah Berbasis
Integrasi. Jakarta: RajaGrafindo Persada.

Winkel, dan Hastuti. 2008. Bimbingan dan Konseling Kelompok. Jakarta: Rineka Cipta.

Young, A. C., Reiser, R. A., \& Walter, D. (1998). Do Superior Teachers Employ Systematic Instructional Planning Procedures? A Descriptive Study. (2), 66-78. 